\title{
Hunting-induced defaunation drives increased seed predation and decreased seedling establishment of commercially important tree species in an Afrotropical forest
}

\author{
Cooper Rosin*, John R. Poulsen \\ Nicholas School of the Environment, Duke University, 450 Research Drive, Durham, NC 27708, USA
}

\section{A R T I C L E I N F O}

\section{Article history:}

Received 14 July 2016

Received in revised form 3 October 2016

Accepted 7 October 2016

\section{Keywords:}

Aucoumea klaineana

Lophira alata

Selective logging

Rodents

Timber

Trophic cascade

\begin{abstract}
A B S T R A C T
Human hunting is widespread in tropical forests and can substantially alter the plant-animal interactions that drive tree recruitment. Seed predation is a strong determinant of plant reproductive success, but it remains unclear how defaunation modifies this process. We examined the effects of hunting-induced defaunation on seed predation and seedling establishment, using replicated exclosure treatments at six sites across a defaunation gradient in northeastern Gabon. We monitored 5580 seeds of eight commercially important tree species that varied in seed traits such as size and dispersal mode. Rodents caused the greatest seed mortality for all species, removing $\sim 60 \%$ of accessible seeds. In comparison, invertebrates and fungi together caused just $6 \%$ of seed mortality. With protection from rodents, more than twice as many seeds established as seedlings, demonstrating that vertebrate seed predation was a strong filter on recruitment. With increasing defaunation, the proportion of seeds removed by rodents increased significantly, and seedling establishment decreased significantly, for most species. In heavily defaunated sites, with the lowest abundances of large mammals, seed removal by rodents increased by $63 \%$ and seedling establishment decreased by $42 \%$ compared to sites with intact fauna. Diminished seedling establishment is likely to reduce the regeneration of many tree species - including some with commercial importance - in hunted forests, with detrimental economic consequences. In turn, declines in timber regeneration may increase the likelihood that selectively logged forests are converted to nonforest land uses with little conservation value. Appropriate management could preclude these outcomes, to the benefit of both wildlife and natural timber regeneration.
\end{abstract}

(c) 2016 Elsevier B.V. All rights reserved.

\section{Introduction}

The ecological processes facilitated by wildlife are increasingly recognized as central to tropical forest tree recruitment. Human hunting disrupts these interactions when it causes defaunation of larger species, resulting in trophic cascades that can reduce plant diversity (Camargo-Sanabria et al., 2014; Harrison et al., 2013) and carbon storage (Kurten et al., 2015; Osuri et al., 2016; Poulsen et al., 2013), and may be detrimental to the regeneration of commercially important timber species (Rosin, 2014). As hunting is widespread in timber concessions (Auzel and Wilkie, 2000; Fimbel et al., 2001; Robinson et al., 1999) and can affect animal abundance more strongly than the direct effects of logging (Bello et al., 2015; Poulsen et al., 2011; van Vliet and Nasi, 2008), understanding the consequences of defaunation is a priority for both for-

\footnotetext{
* Corresponding author.

E-mail address: cooper.rosin@duke.edu (C. Rosin).
}

estry and conservation. Most studies of defaunation have focused on the reduction of large-bodied seed dispersers and the loss or modification of their services (e.g. Terborgh et al., 2008; Brodie et al., 2009; Beaune et al., 2013). Other plant-animal interactions have received substantially less attention, and large gaps remain in our understanding of the consequences of defaunation for tree recruitment.

Seed predators play a crucial role in determining plant reproductive success and species coexistence, by shaping spatial and temporal patterns of seed mortality (Crawley, 1992; Hulme, 1998; Janzen, 1971; Paine and Beck, 2007). Mammalian seed predators, particularly rodents, are often implicated with causing the greatest seed mortality overall (Hulme, 1998; DeMattia et al., 2004; Notman and Villegas, 2005). Because changes in mammal composition and abundance can affect seed and seedling predation (Asquith et al., 1997; DeSteven and Putz, 1984; Sork, 1987), hunting may alter patterns of tree recruitment in defaunated forests, but the effects are not clear. Some studies posit that higher abun- 
dances of rodents in forests without large mammals increase levels of seed predation, but only for small-seeded trees, while largeseeded trees benefit from decreased seed predation by largebodied vertebrates (Beckman and Muller-Landau, 2007; Dirzo et al., 2007; Roldán and Simonetti, 2001). In contrast, Asquith et al. (1997) and Galetti et al. (2015a) documented increased seed predation for medium and large-seeded tree species at sites where only rodents remained of the terrestrial mammalian herbivore/granivore community. With the studies to date limited to a few species and sites in the Neotropics, it is difficult to determine: (a) whether these trends are generalizable, or represent site-specific or species-specific cases; (b) whether these effects may be correlated with seed traits; and (c) whether changes in the strength of seed predation occur incrementally or only after some defaunation threshold has been reached.

Hunting may affect the strength of seed predation for many plant species, though our understanding of this process is limited, especially in Central Africa. There is some evidence that vertebrate seed and seedling predation are strong determinants of tree recruitment in the region (Clark et al., 2012). However, the importance of seed traits and the role of the different taxa of seed predators have yet to be determined, both for intact and anthropogenically disturbed forests. Such studies are rare, given the challenges of quantifying wildlife abundance and composition and establishing manipulative field experiments across a large geographic area. Ultimately, the effects of defaunation on seed predation may depend on the relative importance of the different taxa of seed predators, with little to no effect if invertebrates or fungi are greater seed mortality agents than rodents and other vertebrates.

We took advantage of a known gradient in animal abundance and composition in northeastern Gabon to determine whether hunting-induced defaunation affects seed predation and seedling establishment of tropical forest trees. We selected eight common tree species that vary across seed traits such as size and dispersal mode, to determine the role of seed traits in removal and predation. We hypothesized that increasing defaunation would be positively correlated with seed removal by rodents, particularly for small and medium-sized seeds, resulting in decreased seedling establishment for all but the largest seed species. We focused our study on tree species that are commercially important, to assess both the ecological and potential economic consequences of hunting-induced defaunation for seed predation and seedling recruitment.

\section{Methods}

\subsection{Study area and site selection}

We conducted this study in the Ogooué-Ivindo province of northeastern Gabon. This region is dominated by lowland forest, and receives approximately $1700 \mathrm{~mm}$ of rain annually, with two rainy seasons (September-December and March-June). The study area includes the northern section of Ivindo National Park, the town of Makokou and surrounding villages, and two active logging concessions, which together form a roughly $2170 \mathrm{~km}^{2}$ landscape with high heterogeneity in animal abundance and composition (Fig. 1). Koerner et al. (2016) quantified wildlife community composition and abundance in the area using repeated surveys of 24 randomly-located $2-\mathrm{km}$ transects over a period of 12 months. Their study demonstrated a 30-km gradient in defaunation, with declining diversity and relative abundance of large mammals near villages compared to the relatively intact forests of the Ivindo National Park, far from human settlements.

Within this known defaunation gradient, we selected six of the 24 sites for our seed predation experiment. We selected sites to encompass the full gradient of mammal composition and abundance, including two protected nonhunted sites in the Park, a protected but occasionally hunted site in the buffer zone of the Park, an unprotected hunted site with minor selective timber extraction near a small village, and two hunted sites in an active selective logging concession (Fig. 1). The distance between a site and its nearest neighbor ranged from $6.8 \mathrm{~km}$ to $13.5 \mathrm{~km}$, with $49.5 \mathrm{~km}$ separating the two sites located farthest apart.

\subsection{Seed predation treatments and experimental design}

We quantified rates of seed predation using four exclosure replicates at each of our six sites along the defaunation gradient. A single replicate consisted of 10 scattered seeds of a single tree species in each of three treatments: (1) Open, leaving seeds unprotected from predators, (2) Partial, excluding large but not small vertebrates from accessing seeds, and (3) Closed, excluding all vertebrates (Fig. 2). For each treatment, we cleared approximately half the volume of leaf litter from a ground area of $0.6 \mathrm{~m} \times 0.6 \mathrm{~m}$ to facilitate visual seed monitoring. To construct the exclosures, we erected four $45 \mathrm{~cm}$ tall plastic-coated steel garden stakes to support galvanized $1.3 \mathrm{~cm}$ mesh hardware cloth walls and a roof, secured with zip ties. To exclude all vertebrates from the Closed exclosure, we folded the base of the hardware cloth flush with the soil and secured it with $15 \mathrm{~cm}$ lawn staples. To allow the terrestrial entry of small mammals in the Partial exclosure, we elevated the base of the hardware cloth $10 \mathrm{~cm}$ off the ground - this allowed for the entry of all rodents and other terrestrial mammals up to and including the African brush-tailed porcupine (Atherurus africanus; mass $\leqslant 4 \mathrm{~kg}$ ), but excluded all larger mammals, including duikers (Cephalophus spp.), red river hogs (Potamochoerus porcus), and mandrills (Mandrillus sphinx). Terrestrial primates - mandrills, chimpanzees (Pan troglodytes), and gorillas (Gorilla gorilla) - were excluded from the Partial exclosures based on size but may have had the ability to reach under the elevated exclosures to access seeds if desired, though we have no evidence that this occurred. We established all replicates $10 \mathrm{~m}$ to the right or left of the transect line and separated them by $100 \mathrm{~m}$ from each other.

We quantified seed predation for eight tree species: Antrokaryon klaineanum, Aucoumea klaineana, Dacryodes buettneri, Gambeya lacourtiana, Lophira alata, Pentaclethra macrophylla, Piptadeniastrum africanum, and Pycnanthus angolensis (Table 1). We selected these species based on the following criteria: (a) they were available in sufficient quantities (with a minimum of three reproductive adult trees producing a collective minimum of 720 viable seeds); and (b) they were commercially important, as known timber tree species (Mark et al., 2014). Among the tree species that met these two criteria, we chose species whose seeds varied across several plant functional traits, including seed size and hardness, diaspore type, and dispersal mode. Our focal species varied in seed mass 300fold (from $0.1 \mathrm{~g}$ to $30 \mathrm{~g}$ ), spanned a range in seed coat hardness from very soft to very hard, and included four animal-dispersed, three wind-dispersed, and one gravity/ballistically-dispersed species (Table 1). For each seed species, we collected and mixed seeds from a minimum of three trees. Prior to seed sowing, we cleaned any flesh off the seeds by hand or with a dull knife, and visually inspected each seed, discarding seeds with any sign of fungal or arthropod damage.

After seed placement, we checked the experimental replicates monthly. We noted germination as the visible emergence of a shoot, and removal as the absence of the seed from the treatment area. For seeds that failed to germinate within one month of the first instance of germination in that replicate, we visually inspected seeds and identified the apparent agent of mortality when applicable: fungal spores indicated fungus, while larvae, bore holes, or hollowed seeds indicated invertebrates. We concluded each exper- 


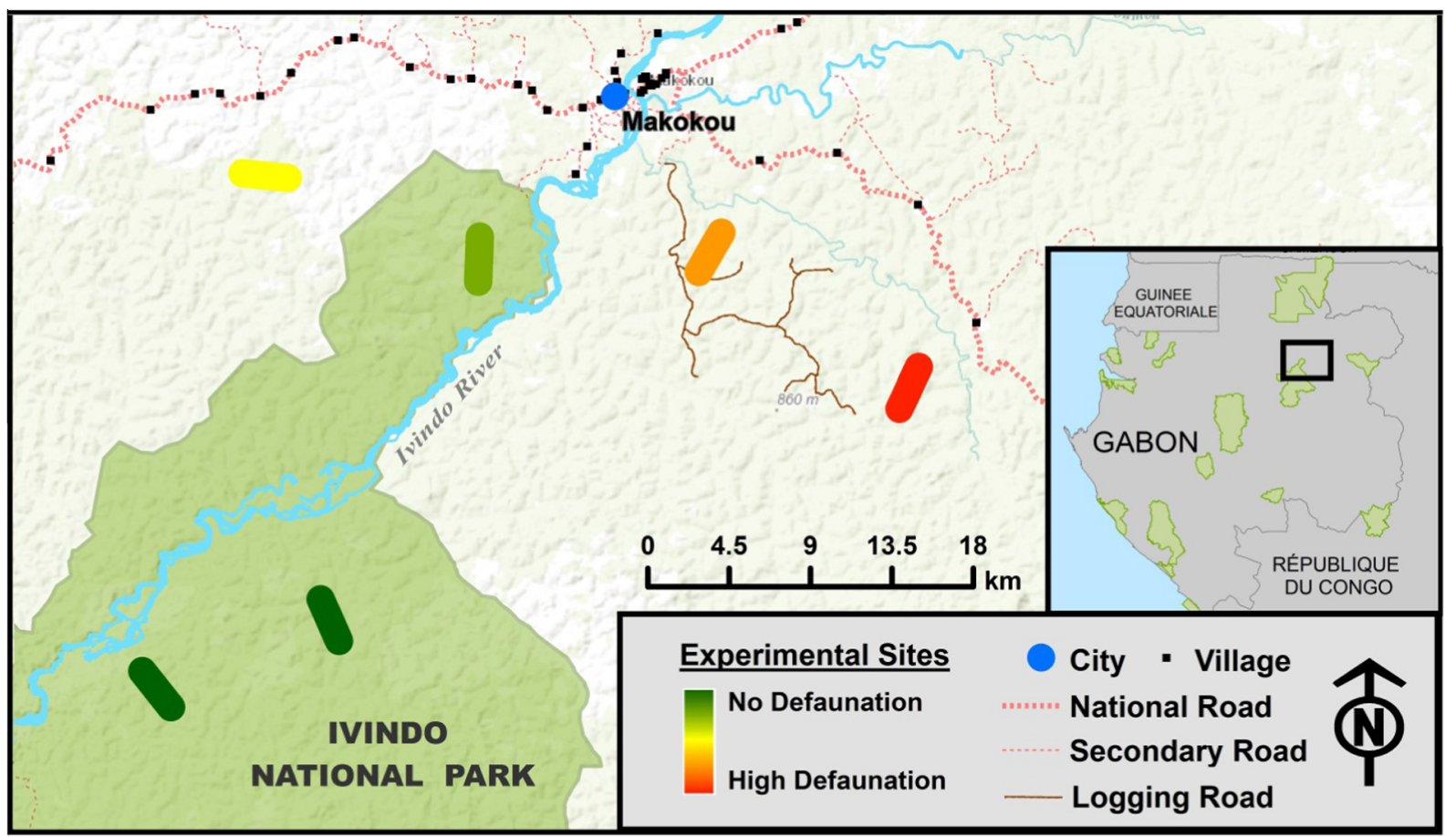

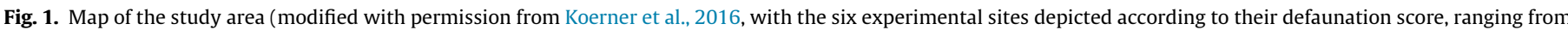
0 (no defaunation) to 1 (high defaunation)). The inset map shows the location of the study area within Central Africa.

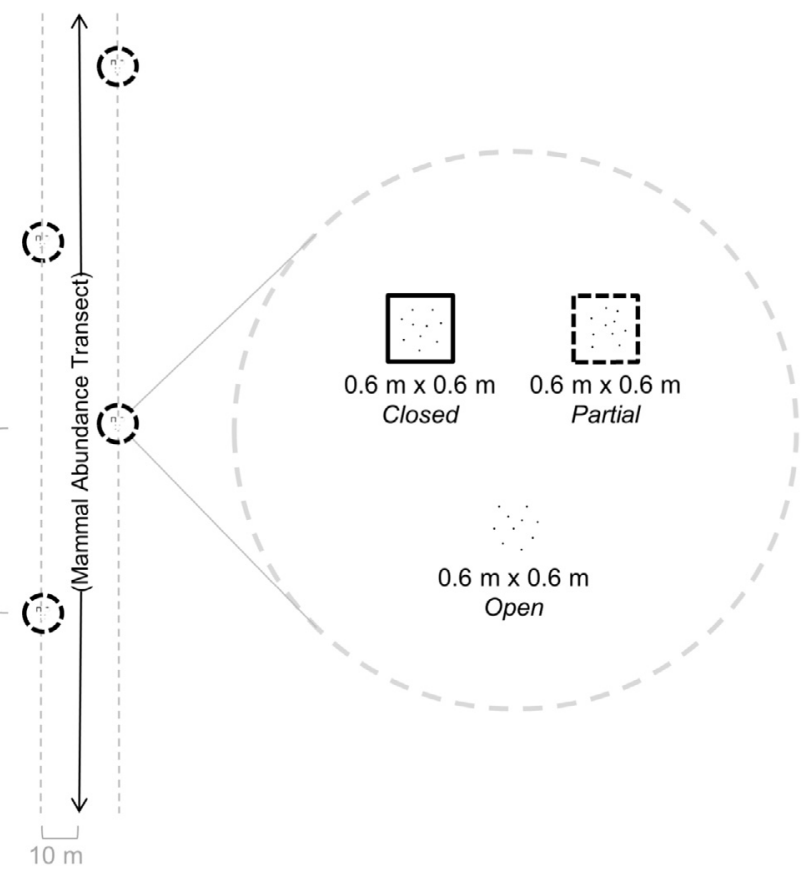

Fig. 2. Seed predation experimental design, featuring four replicates (dashed circles) of three exclosure treatments, each with 10 scattered seeds of a single tree species. The Open treatment left seeds unprotected, the Partial treatment excluded large but not small vertebrates from accessing seeds, and the Closed treatment excluded all vertebrates. This design was repeated for eight seed species at each of six sites across a gradient of defaunation.

iment after all seeds had established as seedlings (with no seed endosperm remaining), or had been removed or killed. As seed availability varied seasonally with fruiting phenology, we established new exclosure treatments for additional species over the course of a year.

\subsection{Data analysis}

To evaluate the strength of seed predation in relation to the degree of defaunation, we developed an index of defaunation for our sites. From the wildlife data collected along transects, Koerner et al. (2016) calculated mammal species richness, evenness, and Shannon-Weiner diversity values for each transect, and used non-metric multidimensional scaling (NMDS) to represent transects in multidimensional space according to their similarity in these metrics. The NMDS axis scores correlated strongly with observed hunting signs along each transect. To create an index of mammalian defaunation, we re-scaled the calculated NMDS values to range from 0 (no defaunation) to 1 (high defaunation) across our sites, assigning a "defaunation score" for each site.

To assess the strength of seed predation across the defaunation gradient, we fitted generalized linear models (GLMs) to individually evaluate the number of seeds with a given fate (establishment, vertebrate removal, invertebrate mortality, and fungus mortality) as a function of the total number of seeds scattered. We included the exclosure treatment type and defaunation score (by site) as explanatory variables. We initially fit all models with a binomial error distribution, but re-fit all models with a quasibinomial error distribution to account for overdispersion. We used linear regression to graphically represent the relationship between defaunation and each seed fate category. We also used linear regression models to represent the effects of defaunation on seed removal for each species individually, but we replaced the linear model with a polynomial model if the Akaike Information Criterion (AIC) value was $\geqslant 3$ points lower. We performed all statistical analyses in $\mathrm{R}$ 3.2.3 (R Development Core Team, 2015).

\section{Results}

We quantified seed predation on a total of 5580 seeds of eight species. Across all sites and species in the Open treatment ( $n=1860$ seeds), $25 \%$ of seeds established as seedlings, $62 \%$ were 
Table 1

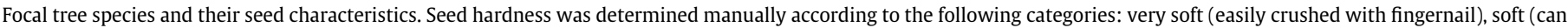

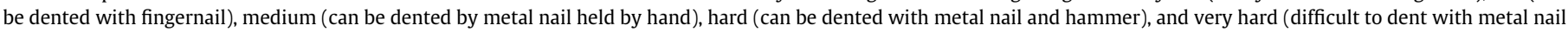
and hammer).

\begin{tabular}{|c|c|c|c|c|c|c|}
\hline Scientific name & Family & Seed mass (g) & Seed length (mm) & Seed hardness & Diaspore type & Dispersal mode \\
\hline Antrokaryon klaineanum & Anacardiaceae & $1.7 /<0.1^{\mathrm{a}}$ & 21 & Very hard & Fleshy & Animal \\
\hline Aucoumea klaineana & Burseraceae & 0.1 & 32 & Soft & Winged & Wind \\
\hline Dacryodes buettneri & Burseraceae & 4.6 & 34 & Medium & Fleshy & Animal \\
\hline Gambeya lacourtiana & Sapotaceae & 2.8 & 29 & Hard & Fleshy & Animal \\
\hline Lophira alata & Ochnaceae & 1.7 & 33 & Soft & Winged & Wind \\
\hline Pentaclethra macrophylla & Fabaceae & 29.4 & 64 & Hard & Pod & Ballistic/gravity \\
\hline Piptadeniastrum africanum & Fabaceae & 0.1 & 12 & Very soft & Winged & Wind \\
\hline Pycnanthus angolensis & Myristicaceae & 1.4 & 18 & Medium & Fleshy & Animal \\
\hline
\end{tabular}

a $1.7 \mathrm{~g}$ refers to mass of stone containing $4-5$ seeds, $<0.1 \mathrm{~g}$ refers to mass of each individual endosperm.

removed by vertebrates, $5 \%$ killed by invertebrates, $1 \%$ killed by fungi, and $7 \%$ germinated but failed to establish for unknown reasons (Fig. 3). In the Partial treatment ( $\mathrm{n}=1860$ seeds), $25 \%$ of seeds established as seedlings, $58 \%$ were removed by vertebrates, $8 \%$ killed by invertebrates, $1 \%$ killed by fungi, and $8 \%$ germinated but failed to establish for unknown reasons. In the absence of vertebrates (Closed treatment, $\mathrm{n}=1860$ seeds), $55 \%$ of seeds established as seedlings, $27 \%$ were killed by invertebrates, $5 \%$ killed by fungi, and $13 \%$ germinated but failed to establish.

With increasing defaunation, the proportion of seeds removed by vertebrates increased significantly (Fig. 5; seed removal GLM: $d f=560, p<0.001$ ); this pattern can be attributed primarily to rodents, as the overall seed removal rates for the Partial (small mammals only) and Open (all mammals) treatments were nearly equal (58\% and $62 \%$, respectively; Fig. 5). This trend held true for five of the eight species individually, while the three exceptions, Pentaclethra macrophylla, Antrokaryon klaineanum, and Piptadeniastrum africanum, showed no significant differences in removal across the defaunation gradient (Fig. 4). P. macrophylla was removed at very high rates across all sites $(90 \%$ of 440 seeds were

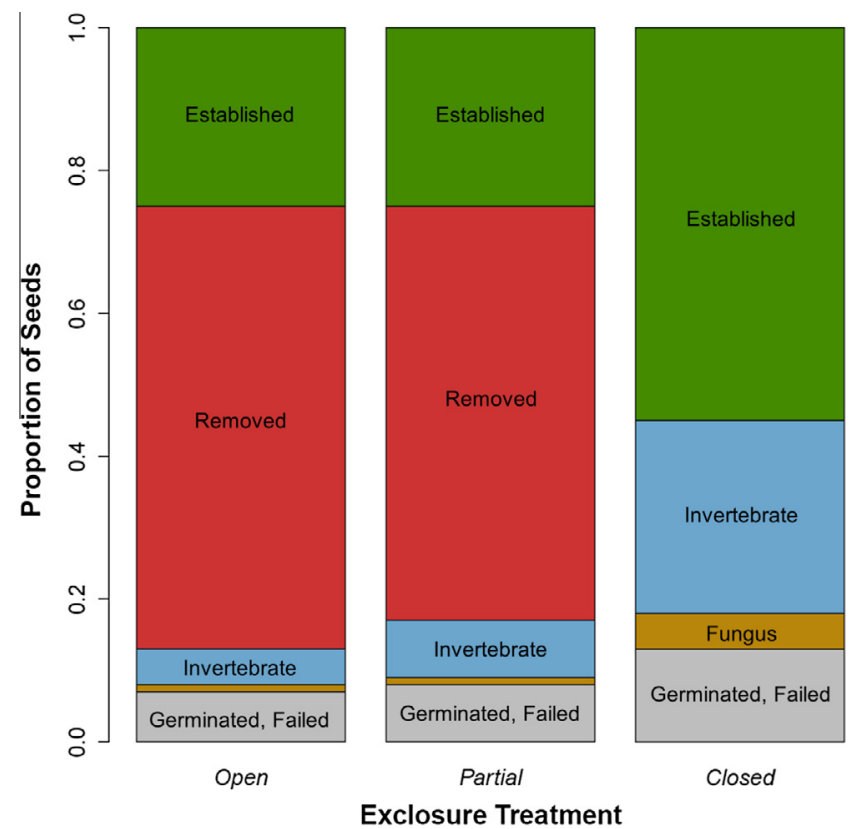

Fig. 3. Fate of all seeds across three exclosure treatments: Open left seeds unprotected, Partial excluded large but not small vertebrates, and Closed excluded all vertebrates. Seed fate categories include: established (seedling with no seed endosperm remaining), removed, invertebrate killed, fungus killed, and germinated but failed to establish for unknown reasons. Removal from the Open and Partial treatments was approximately equal, attributable primarily to rodents, and seedling establishment was more than twice as high with their exclusion. removed from the Partial and Open treatments), while A. klaineanum and $P$. africanum had low removal rates across all sites $(29 \%$ and $13 \%$ of 480 seeds were removed, respectively).

In contrast to the trend in vertebrate seed removal, the proportion of seeds killed by invertebrates and fungi did not change significantly across the defaunation gradient (invertebrate GLM: $d f=560, p=0.315$; fungus GLM: $d f=560, p=0.066$ ).

Corresponding to increased seed removal by rodents, the proportion of seeds that established as seedlings decreased significantly with increasing defaunation (Fig. 5; seedling establishment GLM: $d f=560, p<0.001)$. This overall trend held true for five of the eight species individually. As with the proportions of seeds removed, the establishment of Pentaclethra macrophylla, Antrokaryon klaineanum, and Piptadeniastrum africanum did not change along the defaunation gradient: with no change in seed removal for these species, there was no change in seedling establishment.

\section{Discussion}

\subsection{Role of vertebrates in seed predation and seedling establishment}

Vertebrates drove the loss of more seeds than all other mortality factors combined, for each tree species individually and for all eight species together. Rodents in particular removed approximately $60 \%$ of all accessible seeds, making them the most important actors in the seed predation process in this study. For seeds accessible to rodents, invertebrates and fungi were much less prominent mortality agents, killing just $6 \%$ of seeds combined. Though invertebrates and fungi can disproportionately generate distance- and density-responsive patterns of seed mortality (Hammond and Brown, 1998; Terborgh, 2012; Bagchi et al., 2014; Fricke et al., 2014; but see Hautier et al., 2010), our results support the assertion that mammalian seed predators, particularly rodents, cause the greatest seed mortality overall (Terborgh et al., 1993; DeMattia et al., 2004; Notman and Villegas, 2005), at least for seeds not located under reproductive conspecific trees. Among the terrestrial rodent seed consumers in our study region (small Murid rats and mice [mass $\leqslant 170 \mathrm{~g}$ ], Emin's giant pouched rat [Cricetomys emini; mass $\approx 1200 \mathrm{~g}$ ]), and the African brush-tailed porcupine [Atherurus africanus; mass $\approx 2750 \mathrm{~g}$ ], only A. africanus is known to disperse intact scatterhoarded seeds, though the vast majority of seeds removed by the rodent community are larderhoarded or consumed on the spot (Rosin and Poulsen, 2016). Based on this prior seed fate research, we suspect that $C$. emini was responsible for removing the majority of medium and large seeds in this study, while smaller Murid rats and mice removed the smaller seeds, none of which were likely to have survived.

Given protection from rodents, more than twice as many seeds established as seedlings ( $55 \%$ vs. $25 \%$; Fig. 3 ), demonstrating that vertebrate seed predation was a strong filter on recruitment in 

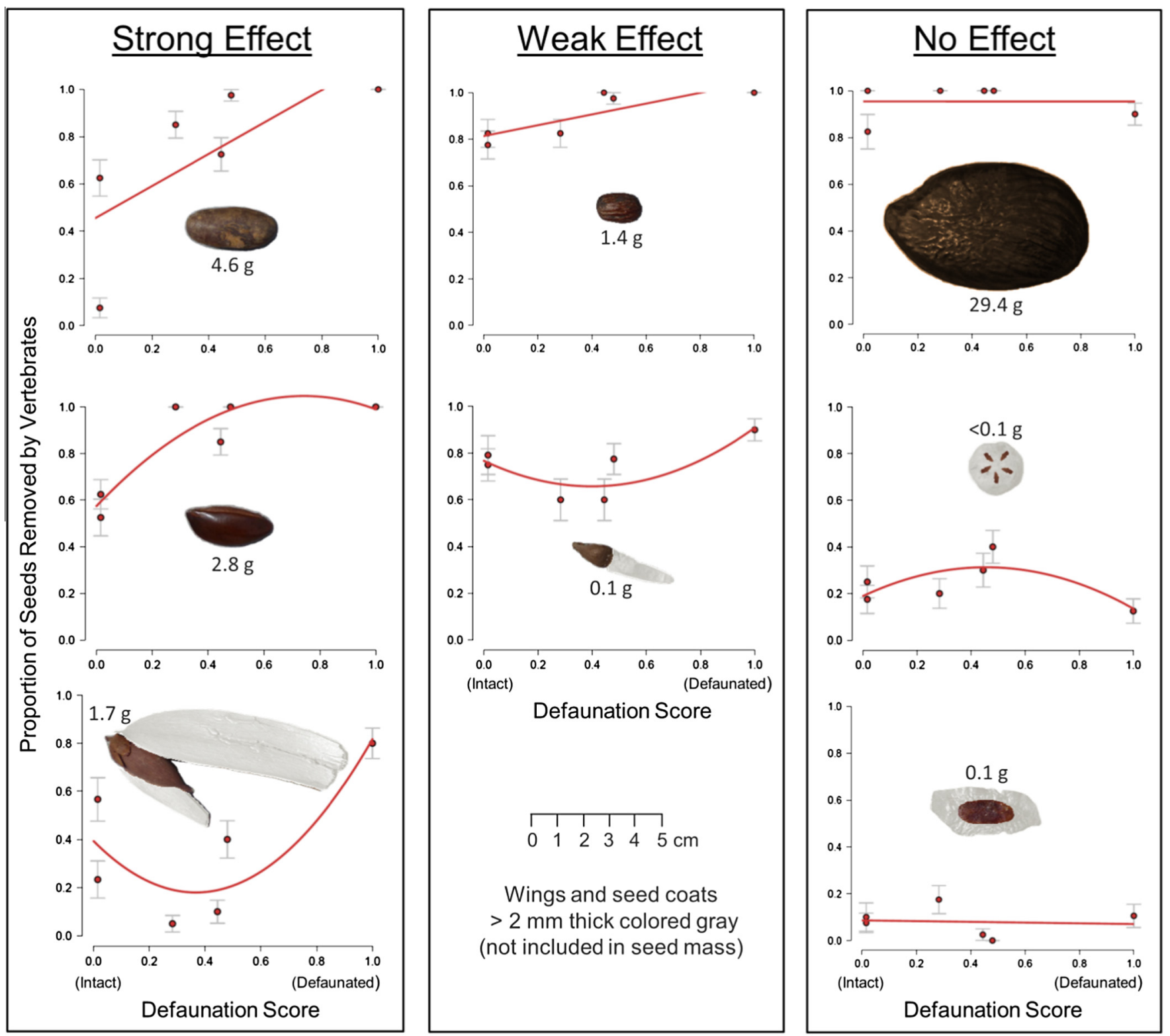

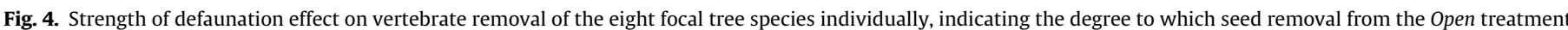

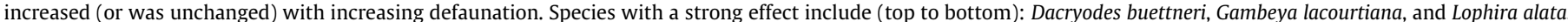

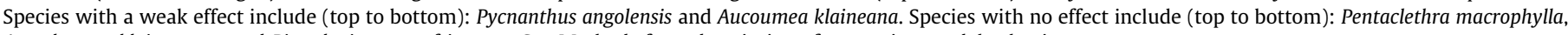
Antrokaryon klaineanum, and Piptadeniastrum africanum. See Methods for a description of regression model selection.

our study. Rodents can clearly reduce the population of seeds that survive to germination and establishment, but whether seed predation affects plant demography at the community level has been subject to some debate. Seed predation may have little effect if establishment is limited by the availability of suitable microsites rather than the number of surviving seeds (Crawley, 1992; Hulme, 1998), though this appears to be uncommon in most plant communities (Hulme, 2002). Indeed, in one study in the Congo Basin, seed limitation induced by vertebrate consumption was the strongest determinant of seedling recruitment (Clark et al., 2012). Rodents may be especially strong drivers of recruitment (Asquith et al., 1997; Dirzo et al., 2007; Kasenene, 1980), reducing seedling density and potentially increasing seedling species richness by favoring common and large-seeded species, thus generating a rare-species advantage (Paine and Beck, 2007). Though we did not assess the role of rodents or other vertebrates on longterm seedling survival or plant community composition, our results highlight the importance of rodent seed consumers in shaping the seed-to-seedling transition stage of a diverse group of tree species.

\subsection{Effects of defaunation}

Increasing defaunation drove increased seed removal and decreased seedling establishment in a consistent and unidirectional manner (Fig. 5). Across the regional extremes of defaunation for our study - from the two sites in Ivindo National Park to the two hunted and logged concession sites - rodent seed removal increased by $63 \%$ and seedling establishment decreased by $42 \%$. Our results indicate that hunting, logging, or a combination of the two can generate substantial changes in the rodent community and the ecological processes they facilitate.

The specific mechanism(s) by which defaunation alters tropical forest rodent communities is not well established. Hunters prefer- 


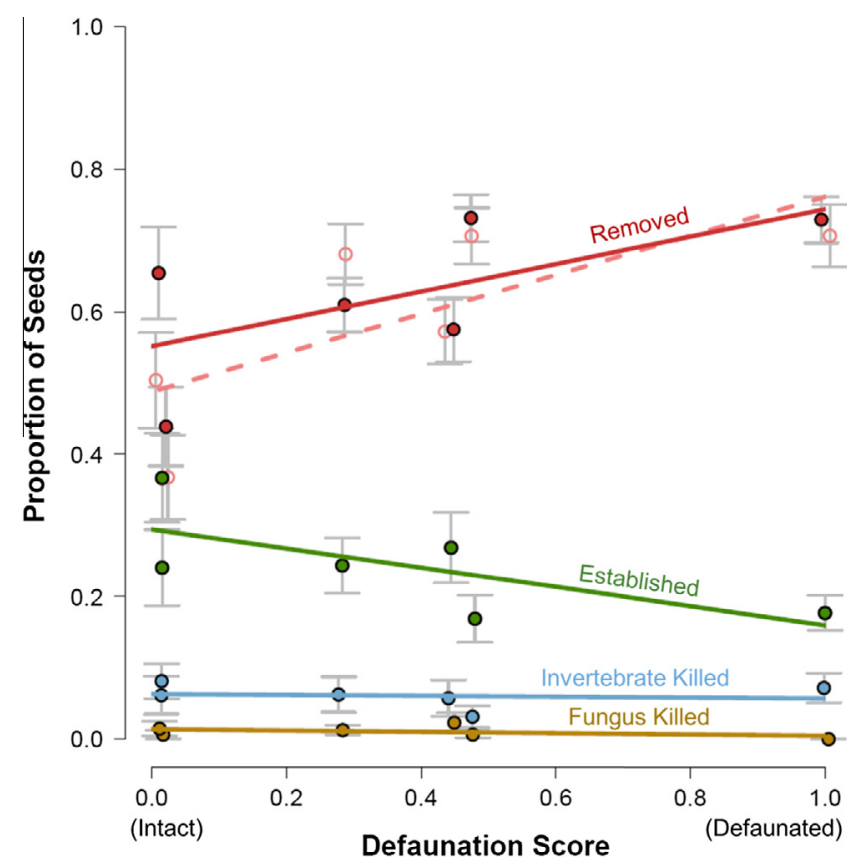

Fig. 5. Fate of Open treatment seeds (all species) across the mammalian defaunation gradient, labeled and colored by fate category (see Fig. 3); the dotted line represents seed removal from the Partial treatment, attributable to rodents. With increasing defaunation (values closer to 1 ), seed removal by rodents increased, seedling establishment decreased, and the proportion of seeds killed by invertebrates and fungi remained approximately the same.

entially harvest large mammals rather than small ones (Fa et al., 2005; Poulsen et al., 2009), potentially releasing rodents from competition for resources with larger mammals and allowing them to expand their dietary breadth (Galetti et al., 2015c). The combination of uneven harvest rates of wildlife species and compensatory ecological responses may lead to increased rodent abundance with hunting, despite a decline in total animal biomass (Effiom et al., 2013; Galetti et al., 2015c; Happold, 1995; Laurance et al., 2006; Phillips, 1997; Poulsen et al., 2011; Wright, 2003). For our region in Gabon, two recent studies have documented community-level increases in rodent biomass with hunting pressure (Koerner et al., 2016; Markham, 2015). Logging itself may also benefit rodents, as the creation of new canopy gaps and expanded road margins increases vegetation density (Malcolm and Ray, 2000; Struhsaker, 1997). As two of our most defaunated sites are within logging concessions, and a third has been subjected to some selective timber harvest by local villagers, it is possible that changes to the seed predation process presented here are a consequence of both pressures, rather than hunting alone. However, Koerner et al. (2016) examined the trends in mammal abundance and composition for these sites, and found that vegetation characteristics such as canopy cover and understory stem density were less important than hunting pressure in driving the abundance of all mammal taxa, with the exception of elephants. Hunting clearly exerts strong pressures on the animal community, and rodents can benefit as a result.

The effects of hunting-induced defaunation on rodent seed predation in our study were fairly consistent across a diverse group of tree species and seed traits, with increased seed removal and decreased seedling establishment for five of the eight focal timber tree species (Fig. 4). The three tree species for which defaunation did not significantly affect seed predation and seedling establishment had traits that made them either very attractive or very unattractive to seed consumers across all sites (Table 1 ). The seeds of $P$. macrophylla, which had the highest rate of vertebrate removal among all species, are large and conspicuous ( $30 \mathrm{~g}$, and shiny brown), relatively unprotected physically (with a thin and easily penetrable seed coat), and are readily consumed by a variety of animals (Rosin, personal observation). Contrary to some results from the Neotropics (Beckman and Muller-Landau, 2007; Dirzo et al., 2007; Roldán and Simonetti, 2001), we found no uppersize-limit on rodent seed predation among our species, with high removal of even the largest seeds we studied. The seeds of A. klaineanum and $P$. africanum, in contrast, were removed at very low proportions across all sites. A. klaineanum seeds have very hard seed coats surrounding several tiny embryos, and $P$. africanum seeds have small and thin papery endosperms - both traits that apparently render these species' seeds unattractive to rodent seed predators.

In defining plant community "winners" and "losers" in the defaunation process - those for which hunting appears to be beneficial or detrimental to their recruitment - it is clear that changes to the seed predation process produce disproportionately more losers, with declining seedling establishment for most species in our study and unchanged seedling establishment for the others. The few species that may benefit from defaunation are likely those possessing seed traits that deter rodent consumers, such as extremely small size or strong chemical and/or physical defenses, or perhaps those that are so rare as to escape the search image of foraging seed predators (Galetti et al., 2015b; Paine and Beck, 2007). Although the scope of this study is limited to the seed-toseedling transition, modifications to the seed predation process that affect the relative abundance of seedling species may persist through the sapling and adult tree stages, and could result in reduced stem density and altered plant community composition (Dirzo et al., 2007; Paine and Beck, 2007).

\subsection{Implications for timber regeneration and management}

The cascading effect of defaunation on seedling regeneration is likely to have economic consequences for timber harvest. Increased seed removal and decreased seedling establishment of many tree species - including but not limited to those harvested for timber - will result in fewer saplings, and eventually fewer harvestable trees in forests subjected to hunting. Many commercially important timber tree species could suffer reduced recruitment as a result (Rosin, 2014). In Uganda, for example, increased rodent abundance drove reduced regeneration of several timber species (Kasenene, 1984, 1980; Struhsaker, 1997). Likewise, abundant small rodents in a defaunated Costa Rican forest removed significantly more seeds of three timber species (Dipteryx panamensis, Minquartia guianensis, and Virola koschnyi) than in a comparable nonhunted site (Guariguata et al., 2002, 2000). Forest managers expecting continued yields must weigh short-term financial and political priorities with the long-term benefits of maintaining intact animal communities (Smith and Garnett, 2004). As it is essential that the processes that contribute to regeneration occur within logged areas themselves (Guariguata and Pinard, 1998), managers must strive to maintain wildlife populations and reduce the impacts of hunting across entire concession areas.

Hunting is widespread in timber concessions, but could be reduced with appropriate management, to the benefit of both wildlife and the natural regeneration of timber species. Timber certification bodies such as the Forest Stewardship Council (FSC) - which provide an external incentive for improved practices - should strive to promote the specific management of ecological processes facilitated by wildlife. As external incentives are not always effective, forest managers may be motivated by improved knowledge of an internal incentive: that hunting can be detrimental to timber regeneration, and may represent an overall economic loss for timber companies that allow hunting in their concessions. The best 
management strategies, regardless of the motivation, will be those that restrict forest access for hunters and their game, and reduce the demand for wild meat by providing or subsidizing other sources of protein (Auzel and Wilkie, 2000; Clark et al., 2009; Poulsen et al., 2009; Rosin, 2014).

To the extent that scientific evidence directs these management decisions, future research should focus on understanding how other ecological processes vary across a gradient of defaunation, as well as how these changes might translate to shifts in plant community composition and actual gains or losses in timber tree abundance. Selectively logged forests can represent a "middle way" between absolute protection and deforestation (Putz et al., 2012), but reduced regeneration as a result of hunting may increase the likelihood that these forests be converted to nonforest land uses, representing a great loss of conservation value. It is thus critical that researchers and managers alike strive to address specific conservation needs and identify viable alternatives to exploitative hunting practices.

\section{Acknowledgements}

We thank Rachel Rosin, Lucien Amvame, Jeannot Mbelassanga, Kendall Beals, Michael Belovitch, Ruby Harrison, Megan Pendred, Ernest Assadjola, Roger Kowe, Guy Moussavou, and Nicolas Yao for assistance in the field. We also thank the Gabonese government, including the Agence Nationale des Parcs Nationaux (ANPN) and the Centre Nationale de la Recherche Scientifique et Technique (CENAREST), for permission to conduct the research and for their administrative and logistical support. We thank Roland Kays, John Terborgh, Mauro Galetti, and one anonymous reviewer for their constructive comments on an earlier version of the manuscript. This work was financially supported by the Duke University Graduate School and the Garden Club of America.

\section{Appendix A. Supplementary material}

Supplementary data associated with this article can be found, in the online version, at http://dx.doi.org/10.1016/j.foreco.2016.10. 016.

\section{References}

Asquith, N.M., Wright, S.J., Clauss, M.J., 1997. Does mammal community composition control recruitment in neotropical forests? Evidence from Panama. Ecology 78, 941-946.

Auzel, P., Wilkie, D., 2000. Wildlife use in Northern Congo: hunting in a commercial logging concession. In: Robinson, J.G., Bennett, E.L. (Eds.), Hunting for Sustainability in Tropical Forests. Columbia University Press, New York, NY, pp. 413-426.

Bagchi, R., Gallery, R.E., Gripenberg, S., Gurr, S.J., Narayan, L., Addis, C.E., Freckleton, R.P., Lewis, O.T., 2014. Pathogens and insect herbivores drive rainforest plant diversity and composition. Nature 506, 85-88. http://dx.doi.org/ 10.1038/nature12911.

Beaune, D., Bretagnolle, F., Bollache, L., Hohmann, G., Surbeck, M., Fruth, B., 2013. Seed dispersal strategies and the threat of defaunation in a Congo forest. Biodivers. Conserv. 22, 225-238. http://dx.doi.org/10.1007/s10531-012-0416-x.

Beckman, N.G., Muller-Landau, H.C., 2007. Differential effects of hunting on predispersal seed predation and primary and secondary seed removal of two Neotropical tree species. Biotropica 39, 328-339. http://dx.doi.org/10.2307/ 30044945.

Bello, C., Galetti, M., Pizo, M.A., Magnago, L.F.S., Rocha, M.F., Lima, R.A.F., Peres, C.A., Ovaskainen, O., Jordano, P., 2015. Defaunation affects carbon storage in tropical forests. Sci. Adv. 1, 1-11. http://dx.doi.org/10.1126/sciadv.1501105.

Brodie, J.F., Helmy, O.E., Brockelman, W.Y., Maron, J.L., 2009. Bushmeat poaching reduces the seed dispersal and population growth rate of a mammal-dispersed tree. Ecol. Appl. 19, 854-863.

Camargo-Sanabria, A.A., Mendoza, E., Guevara, R., Martinez-Ramos, M., Dirzo, R. 2014. Experimental defaunation of terrestrial mammalian herbivores alters tropical rainforest understorey diversity. Proc. R. Soc. B Biol. Sci. 282. http://dx. doi.org/10.1098/rspb.2014.2580. 20142580-20142580.

Clark, C.J., Poulsen, J.R., Levey, D.J., 2012. Vertebrate herbivory impacts seedling recruitment more than niche partitioning or density-dependent mortality. Ecology 93, 554-564. http://dx.doi.org/10.1890/11-0894.1.
Clark, C.J., Poulsen, J.R., Malonga, R., Elkan, P.W., 2009. Logging concessions can extend the conservation estate for Central African tropical forests. Conserv. Biol. 23, 1281-1293. http://dx.doi.org/10.1111/j.1523-1739.2009.01243.x.

Crawley, M.J., 1992. Seed predators and plant population dynamics. In: Fenner, M. (Ed.), Seeds: The Ecology of Regeneration in Plant Communities. CAB International, Wallingford, UK, pp. 157-191.

DeMattia, E.A., Curran, L.M., Rathcke, B.J., Biology, E., Arbor, A., 2004. Effects of small rodents and large mammals on Neotropical seeds. Ecology 85, 2161-2170.

DeSteven, D., Putz, F., 1984. Impact of mammals on early recruitment of a tropical canopy tree, Dipteryx panamensis, in Panama. Oikos 43, 207-216.

Dirzo, R., Mendoza, E., Ortíz, P., 2007. Size-related differential seed predation in a heavily defaunated neotropical rain forest. Biotropica 39, 355-362.

Effiom, E., Nuñez-Iturri, G., Smith, H.G., Ottosson, U., Olsson, O., 2013. Bushmeat hunting changes regeneration of African rainforests. Proc. R. Soc. B, 280.

Fa, J.E., Ryan, S.F., Bell, D.J., 2005. Hunting vulnerability, ecological characteristics and harvest rates of bushmeat species in Afrotropical forests. Biol. Conserv. 121, $167-176$

Fimbel, R., Grajal, A., Robinson, J. (Eds.), 2001. The Cutting Edge: Conserving Wildlife in Logged Tropical Forests. Columbia University Press, New York.

Fricke, E.C., Tewksbury, J.J., Rogers, H.S., 2014. Multiple natural enemies cause distance-dependent mortality at the seed-to-seedling transition. Ecol. Lett. 17 593-598. http://dx.doi.org/10.1111/ele.12261.

Galetti, M., Bovendorp, R.S., Guevara, R., 2015a. Defaunation of large mammals leads to an increase in seed predation in the Atlantic forests. Glob. Ecol. Conserv. 3, 824-830. http://dx.doi.org/10.1016/j.gecco.2015.04.008.

Galetti, M., Guevara, R., Galbiati, L.A., Neves, C.L., Rodarte, R.R., Mendes, C.P., 2015b Seed predation by rodents and implications for plant recruitment in defaunated Atlantic forests. Biotropica 47, 521-525. http://dx.doi.org/10.1111/btp.12246.

Galetti, M., Guevara, R., Neves, C.L., Rodarte, R.R., Bovendorp, R.S., Moreira, M., Hopkins III, J.B., Yeakel, J.D., 2015c. Defaunation affects the populations and diets of rodents in Neotropical rainforests. Biol. Conserv. 190, 2-7. http://dx.doi. org/10.1016/j.biocon.2015.04.032.

Guariguata, M., Claire, H., Jones, G., 2002. Tree seed fate in a logged and fragmented forest landscape, northeastern Costa Rica. Biotropica 34, 405-415.

Guariguata, M.R., Adame, J.J.R., Finegan, B., 2000. Seed removal and fate in two selectively logged lowland forests with constrasting protection levels. Conserv. Biol. 14, 1046-1054. http://dx.doi.org/10.1046/j.1523-1739.2000.99148.x.

Guariguata, M.R., Pinard, M.A., 1998. Ecological knowledge of regeneration from seed in Neotropical forest trees: implications for natural forest management. For. Ecol. Manage. 112, 87-99.

Hammond, D.S.D., Brown, V., 1998. Disturbance, phenology and life-history characteristics: factors influencing distance/density-dependent attack on tropical seeds and seedlings. In: Newbery, D., Prins, H., Brown, N. (Eds.) Dynamics of Tropical Communities. Blackwell Science, Inc., Malden, MA.

Happold, D.C.D., 1995. The interactions between humans and mammals in Africa in relation to conservation: a review. Biodivers. Conserv. 4, 395-414. http://dx.doi org/10.1007/BF00058424.

Harrison, R.D., Tan, S., Plotkin, J.B., Slik, F., Detto, M., Brenes, T., Itoh, A., Davies, S.J., 2013. Consequences of defaunation for a tropical tree community. Ecol. Lett. 16, 687-694. http://dx.doi.org/10.1111/ele.12102.

Hautier, Y., Saner, P., Philipson, C., Bagchi, R., Ong, R.C., Hector, A., 2010. Effects of seed predators of different body size on seed mortality in Bornean logged forest. PLoS One 5, e11651. http://dx.doi.org/10.1371/journal.pone.0011651.

Hulme, P., 2002. Seed-eaters: seed dispersal, destruction and demography. In: Levey, D., Silva, W., Galetti, M. (Eds.), Seed Dispersal and Frugivory: Ecology, Evolution and Conservation. CABI Publishing, New York, pp. 257-273.

Hulme, P., 1998. Post-dispersal seed predation: consequences for plant demography and evolution. Perspect. Plant Ecol. Evol. Syst. 1, 32-46.

Janzen, D.H., 1971. Seed predation by animals. Annu. Rev. Ecol. Syst. 2, 465-492.

Kasenene, J., 1984. The influence of selective logging on rodent populations and the regeneration of selected tree species in the Kibale Forest, Uganda. Trop. Ecol. 25, $179-195$.

Kasenene, J., 1980. Plant Regeneration and Rodent Populations in Selectively Felled and Unfelled Areas of the Kibale Forest. Makerere University, Kampala, Uganda.

Koerner, S.E., Poulsen, J.R., Blanchard, E., Okouyi, J., Clark, C.J., 2016. Hunting alters vertebrate community composition and reduces diversity along a defaunation gradient from rural villages in Gabon. J. Appl. Ecol. (in press)

Kurten, E.L., Wright, S.J., Carson, W.P., 2015. Hunting alters seedling functional trait composition in a Neotropical forest. Ecology 96, 1923-1932. http://dx.doi.org/ 10.1890/14-1735.1.

Laurance, W.F., Croes, B.M., Tchignoumba, L., Lahm, S.A., Alonso, A., Lee, M.E. Campbell, P., Ondzeano, C., 2006. Impacts of roads and hunting on Central African rainforest mammals. Conserv. Biol. 20, 1251-1261. http://dx.doi.org/ 10.1111/j.1523-1739.2006.00420.x.

Malcolm, J.R., Ray, J.C., 2000. Influence of timber extraction routes on Central African small-mammal communities, forest structure, and tree diversity. Conserv. Biol. 14, 1623-1638. http://dx.doi.org/10.1111/j.15231739.2000.99070.x.

Mark, J., Newton, A.C., Oldfield, S., Rivers, M., 2014. The international timber trade: a working list of commercial timber tree species. p. 1-56.

Markham, I., 2015. Of Mice and Men in Gabon: Changes in Rodent Communities Associated with Logging and Hunting Master's Thesis. Duke University.

Notman, E., Villegas, A., 2005. Patterns of seed predation by vertebrate versus invertebrate seed predators among different plant species, seasons, and spatial distributions. In: Forget, P.-M., Lambert, J., Hulme, P., Vander Wall, S. (Eds.), 
Seed Fate: Predation, Dispersal and Seedling Establishment. CABI Publishing, Cambridge, MA, pp. 55-76.

Osuri, A.M., Ratnam, J., Varma, V., Alvarez-Loayza, P., Astaiza, J.H., Bradford, M., Fletcher, C., Ndoundou-Hockemba, M., Jansen, P.A., Kenfack, D., Marshall, A.R., Ramesh, B.R., Rovero, F., Sankaran, M., 2016. Contrasting effects of defaunation on aboveground carbon storage across the global tropics. Nat. Commun. 1-7. http://dx.doi.org/10.1038/pj.2016.37.

Paine, C.E.T., Beck, H., 2007. Seed predation by Neotropical rain forest mammals increases diversity in seedling recruitment. Ecology 88, 3076-3087.

Phillips, O., 1997. The changing ecology of tropical forests. Biodivers. Conserv. 6 291-311.

Poulsen, J.R., Clark, C.J., Bolker, B.M., 2011. Decoupling the effects of logging and hunting on an Afrotropical animal community. Ecol. Appl. 21, 1819-1836.

Poulsen, J.R., Clark, C.J., Mavah, G., Elkan, P.W., 2009. Bushmeat supply and consumption in a tropical logging concession in northern Congo. Conserv. Biol. 23, 1597-1608.

Poulsen, J.R., Clark, C.J., Palmer, T., 2013. Ecological erosion of an Afrotropical forest and potential consequences for tree recruitment and forest biomass. Biol. Conserv. 163, 122-130.

Putz, F.E., Zuidema, P.A., Synnott, T., Peña-Claros, M., Pinard, M.A., Sheil, D., Vanclay, J.K., Sist, P., Gourlet-Fleury, S., Griscom, B., Palmer, J., Zagt, R., 2012. Sustaining conservation values in selectively logged tropical forests: the attained and the attainable. Conserv. Lett. 5, 296-303. http://dx.doi.org/10.1111/j.1755 263X.2012.00242.x.

R Development Core Team, 2015. R: A language and environment for statistical computing. R Foundation for Statistical Computing, Vienna, Austria, ISBN 3 900051-07-0. URL http://www.R-project.org.

Robinson, J., Redford, K., Bennett, E., 1999. Wildlife harvest in logged tropica forests. Science 284 (80), 595-596.
Roldán, A., Simonetti, J.A., 2001. Plant-mammal interactions in tropical Bolivian forests with different hunting pressures. Conserv. Biol. 15, 617-623.

Rosin, C., 2014. Does hunting threaten timber regeneration in selectively logged tropical forests? For. Ecol. Manage. 331, 153-164. http://dx.doi.org/10.1016/ j.foreco.2014.08.001.

Rosin, C., Poulsen, J.R., 2016. Telemetric tracking of scatterhoarding and seed fate in a Central African forest. Biotropica (in press).

Smith, K., Garnett, S., 2004. Animal-plant interactions: a rainforest conservation manager's perspective. In: Kanowski, J., Catterall, C., Dennis, A., Westcott, D. (Eds.), Animal-Plant Interactions in Conservation and Restoration: Workshop Proceedings. Cooperative Research Centre for Tropical Rainforest Ecology and Management, Rainforest RCR., Cairns, Australia, pp. 17-19.

Sork, V., 1987. Effects of predation and light on seedling establishment in Gustavia superba. Ecology 68, 1341-1350.

Struhsaker, T., 1997. Ecology of an African Rain Forest. University Press of Florida, Gainesville, FL.

Terborgh, J., 2012. Enemies maintain hyperdiverse tropical forests. Am. Nat. 179, 303-314. http://dx.doi.org/10.1086/664183.

Terborgh, J., Losos, E. Riley, M., Riley, M. 1993. Predation by vertebrates and invertebrates on the seeds of five canopy tree species of an Amazonian forest. Vegetatio 107, 375-386.

Terborgh, J., Nuñez-Iturri, G., Pitman, N.C.A., Valverde, F.H.C., Alvarez, P., Swamy, V., Pringle, E.G., Paine, C.E.T., Nuñez-Iturri, G., 2008. Tree recruitment in an empty forest. Ecology 89, 1757-1768. http://dx.doi.org/10.1890/07-0479.1.

van Vliet, N., Nasi, R., 2008. Mammal distribution in a Central African logging concession area. Biodivers. Conserv. 17, 1241-1249. http://dx.doi.org/10.1007/ s10531-007-9300-5.

Wright, S.J., 2003. The myriad consequences of hunting for vertebrates and plants in tropical forests. Perspect. Plant Ecol. Evol. Syst. 6, 73-86. http://dx.doi.org/ $10.1078 / 1433-8319-00043$. 